\title{
Research of Current Common Languages in Afghanistan
}

DOI: https://doi.org/10.47175/rielsj.v2i4.349

\section{| Pohanyar Hejratullah Mobashir |}

\author{
Parwan University, Charekar, \\ Afghanistan
}

mobesherhejrat@yahoo.com

\begin{abstract}
The Purpose of this academic article is to analyze the current languages of Afghanistan; in addition, the position is studied. Afghanistan has a diverse cultural heritage, which is protected by these languages; the importance of keeping it alive is very high. This research is descriptive and analytical the type of research is librarian and methodical, which is a description of the current popular languages. In this country current languages and dialects thirty summers, each language is based on the number of speakers has its own status and position, which are called official, residual, local and national languages. These languages belong to the most popular groups in the world the famous are Aryan, IndoAryan and Turkish. In addition, the languages of the pro- semiotic and seraiki groups are currently in question.

KEYWORDS

common; official; nation; Local and Residual Languages.
\end{abstract}

\section{INTRODUCTION}

There are dozens of common languages and dialects in different parts of the world, which is spoken by large and small tribes.

Afghanistan is also home to a variety of languages and dialects, in addition to its historical and cultural background, through which many civilization and cultures have been trained. The current languages of this country can be studied in the Residual and Local languages and addition to the national and official languages, that there were many large and small tribes and nations living in this land. So the living nations have always kept their language, history and culture alive.

Most of the current languages spoken in Afghanistan are from the Hand-Aryan family of belongs to Bactrian, Persian, Dardic and Hindi language groups, some of the languages belong to the non-Hindu-Aryan family Turkey and the Seraiki group.

The importance of Afghanistan languages, like other languages of the world, depends on the speaker of those languages. Of these languages it is spoken in many parts of Afghanistan. Other Residual and Local languages represent different cultures.

\section{RESEARCH METHODS}

Qualitive method has used in order to collect the data.

\section{RESULTS AND DISCUSSION}

\section{Content}

The existence of languages is an important issue for history, and the identity of many nations, the mission of civilization is preserved in it. Afghanistan is a multi-lingual and multi-cultural country; there are 30 language and dialects spoken by different ethnic groups in this country, these languages belong to the Indo-European and non-Indo-European languages family groups. 
These languages can be studied in the framework of national, official, regional and remaining languages. Pashto and Dari are official languages of Afghanistan, in addition, each language has its own position in terms of speakers and literature, which are discussed and analyzed here.

\section{Languages Spoken in Afghanistan}

On the soil of contemporary Afghanistan and its immediate vicinity archaeological studies lead researchers to conclude that Afghanistan belongs to the ancient Aryan tribes and is a land of languages. (Shinwari, 2014: 4)

In this series in the caves of Hindu Kush, in hunting ground and large rocks the potential for early human life and the discovery of stone tools on both sides of these mountains and other such evidence proves the above views.

Indo-European families have a total of 200 languages which makes up almost half of the world's population with two billion speakers. (Niazi, 2014: 76)

Most of the languages spoken in Afghanistan belong to this family, but there are also some languages that of the non-Ando European family (Turk, Mongolian, Dravidian, Hami and Argotic) related to languages.

Thirty languages of her family are spoken languages in this land. In the fourth volume of the Ariana encyclopedia a table on the common languages of Afghanistan is mentioned and written about current popular languages: Afghanistan was a crossroads of migration in ancient times and in the Middle Ages. These tribes had different religions, whose specimens are still seen in this country

All of Afghanistan's current languages can be divided into two major groups' IndoEuropean and non-Indo European families. (Ariana encyclopedia, 2011: 285)

\begin{tabular}{|c|c|c|c|c|c|c|c|c|c|}
\hline \multicolumn{5}{|c|}{ non-Indo European } & \multicolumn{5}{|c|}{ Indo- European } \\
\hline \multicolumn{2}{|c|}{$\begin{array}{c}\text { Seraiki language of } \\
\text { Afghanistan }\end{array}$} & \multirow{2}{*}{\begin{tabular}{|c} 
Semitic \\
and Hami \\
$\begin{array}{c}\text { Arabic } \\
\text { (R?) }\end{array}$
\end{tabular}} & \multicolumn{2}{|c|}{ Turkish } & \multicolumn{3}{|c|}{ Indo- Aryan } & \multicolumn{2}{|c|}{ Aryan } \\
\hline Argotic & Dravidian & & $\begin{array}{l}\text { Mong } \\
\text { olian }\end{array}$ & Turkish & $\begin{array}{c}\text { Hindi } \\
(\mathrm{L})\end{array}$ & Dardic & Nuristan & $\begin{array}{c}\text { parsec } \\
\text { (western) } \\
\text { group }\end{array}$ & $\begin{array}{l}\text { Bactrian } \\
\text { (eastern) } \\
\text { group }\end{array}$ \\
\hline \multirow{4}{*}{$\begin{array}{l}\text { Zargari } \\
\text { (L?) }\end{array}$} & \multirow{4}{*}{$\begin{array}{c}\text { Brahui } \\
\text { (L) }\end{array}$} & & \multirow{4}{*}{$\begin{array}{l}\text { Mong } \\
\text { olian } \\
\text { (R?) }\end{array}$} & \multirow{4}{*}{$\begin{array}{l}\text { Uzbek } \\
(\mathrm{N})\end{array}$} & \multirow{4}{*}{$\begin{array}{l}\text { Panjabi } \\
\text { (L) }\end{array}$} & \multirow{4}{*}{\begin{tabular}{|c|} 
Pash \\
ayi \\
$\left(\mathrm{N}^{*}\right)$ \\
\end{tabular}} & \multirow[t]{4}{*}{ Kati $\left(\mathbb{N}^{*}\right)$} & \multirow{2}{*}{$\begin{array}{l}\text { Bolochi } \\
\text { (N) }\end{array}$} & Pashto (O) \\
\hline & & & & & & & & & Shaghni (L) \\
\hline & & & & & & & & \multirow{2}{*}{ southwest } & Roshani (L) \\
\hline & & & & & & & & & \multirow{2}{*}{$\begin{array}{c}\text { Ishkashmi } \\
\left(L^{*}\right)\end{array}$} \\
\hline \multirow{4}{*}{\multicolumn{4}{|c|}{$\begin{array}{l}\text { The Kyrgyz emigrated from Afghanistan } \\
\text { in } 1999 \text { from a nation }\end{array}$}} & \multirow{3}{*}{$\begin{array}{l}\text { Turkmen } \\
(\mathrm{N})\end{array}$} & \multirow{3}{*}{$\begin{array}{l}\text { Sindhi } \\
\text { (L) }\end{array}$} & \multirow{3}{*}{$\begin{array}{c}\text { Gurbati } \\
\text { (L) }\end{array}$} & \multirow[t]{3}{*}{ Ashkenazi } & \multirow[t]{4}{*}{ Dari (O) } & \\
\hline & & & & & & & & & $\begin{array}{l}\text { Sanglichi } \\
\left(\mathrm{L}^{8}\right)\end{array}$ \\
\hline & & & & & & & & & Manji $\left(L^{*}\right)$ \\
\hline & & & & $\begin{array}{l}\text { Uyghur } \\
\text { (L?) }\end{array}$ & $\begin{array}{l}\text { Gujri } \\
(\mathrm{L})\end{array}$ & $\begin{array}{l}\text { Tirahi } \\
\left(\mathrm{R}^{*}\right)\end{array}$ & $\begin{array}{c}\text { Wagley } \\
\left(L^{*}\right)\end{array}$ & & Wakhi (L) \\
\hline & & & & & & & & & Southeast \\
\hline & & & & \multirow{2}{*}{$\begin{array}{c}\text { Kyrgyz } \\
\text { (R?) }\end{array}$} & \multirow{2}{*}{$\begin{array}{l}\text { Inco } \\
\text { (L?) }\end{array}$} & & \multirow{2}{*}{$\begin{array}{c}\text { Person } \\
\left(\mathrm{L}^{*}\right)\end{array}$} & & Armory (R) \\
\hline & & & & & & & & & Parachi $\left(\mathrm{R}^{*}\right)$ \\
\hline
\end{tabular}

\section{Memoir:}

The star indicates that these languages are not spoken across borders. This $(\stackrel{\Upsilon}{)})$ indicates that the existence of this language is currently in question. 
- O. Official languages

- N. Nation languages.

- L. Local languages

- R. Residual languages

In this article, all the current languages of Afghanistan are discussed in the above four sections according to different position.

\section{Official Languages}

The national language of a country is one and its official number, in Canada, for example, there are two official languages, one is English and the other is French, four languages are official in Switzerland, the formation and development of nations has always played a role in the position of national languages.

This is not a condition in the formation of a nation, that the language of this nation be the state, in ancient Russia, India and other countries where power full tribes had passed, the language was one. (Islanov and Mrs. Grasimova, 1964: 2)

The existence of a state is usually a prerequisite for the recognition of a language, there is no official language before the state, but there is a national one. In the law of a state whose official languages are not indicated, the national language is the official language. (Zirakyar, language politics and language planning: www.toloaFghan.com)

Pashto and Dari are the official languages of Afghanistan, all over Afghanistan people of different ethnicities are learning alongside their mother tongue, and so the effects of these languages are evident in other popular languages.

\section{Pashto}

Pashto is one of the most important, living and literary languages of the indo- European family, one of the eastern languages of the Aryan branch. it is one of the leading languages in the world. (Yoon, 2018: 89)

Pashto has been the official language of Afghanistan since 1936, education was also made compulsory in schools and government offices, and in the constitution of 1964, and Pashto was recognized as the national and official language. (Shuaa, 2015: 17)

The national language in Afghanistan preceded the enactment of the constitution. Fifty years ago, Amir Sher Ali Khan, on the recommendation of Sayed Jamaluddin, used the Pashto language for national terminology. During the reign of Amir Habibullah Khan, Allama Mahmood Tarzi used Pashto as the national language in Siraj-ul-akhbar Afghania.

Article 16 of the new draft constitution deals with the languages of Afghanistan:(( Pashto, Dari, Uzbek... and among other languages spoken in the country, Pashto and Dari are the official languages of the state, article 20 of the constitution deals with the anthem of Afghanistan: (The national anthem of Afghanistan is in Pashto) (Rafi, 2017: 145)

\section{Dari}

In addition to Pashto, Dari is also the official language of Afghanistan according to the constitution. Scientific views on the status of this language have been accepted by linguists since the 19th century, he is author of (The Languages of Afghanistan) by renowned French linguist Emile Benvenist, who has written openly about the languages of Afghanistan, especially the Dari language : among the Indo-Aryan languages, the most popular group from the south-western branch is Persian Dari. (Ariana encyclopedia, 2011: 253) 


\section{N. Nation languages}

Specific ethnic groups speak ethnic languages, that languages are the property of the people, and people use it to understand and inform each other, hence most languages are called ethnicities and countries. Such as: Balochi, Pashto, Pashai, Turkmen, Kati are the languages of popular ethnic groups in Afghanistan, which is spoken by people in different parts of the Afghanistan.

\section{Local languages}

Local languages spoken in a particular place, the local languages of Afghanistan include Pamiri( Shughni, Roshani, Ashkashmi, Sangli, Monji, Wakhi), Nuristani (Ashkun and Waigli), and Dardik (Gurbati), also Hindi languages like Punjabi, Sindhi, Gujarati and Inco (Lehnde) language whose existence is current in question, In addition, in the non-IndoEuropean family, Uyghur comes from Turkish, and in the Dravidian group, Brahui.

\section{R. Residual languages}

The remaining languages refer to languages that have a limited number of speakers. There are a number of languages spoken in Afghanistan by a limited number of people, these languages include the Bactrin group (Armory, Parachi, from the Dardic languages, the Tirahi language, and the non-Indo-European family the Turkish groups (Kyrgyz, Mongolian).

In general, most of the people in this country speak Pashto, which number is estimated at more than.

Accurate population figures for Afghanistan are not available, to identify the thro speakers and member each language.

Languages that are nationally memorable, there is development of Pashto as a literary language as well as Dari language. And the government's goal is to spread the culture in both languages across the country.

\section{CONCLUSION}

The current languages of Afghanistan belong to popular groups of Indo-European and nonIndo-European language families. The largest group is the Aryans, in addition to Pashto, Parachi and Armari languages, Pamiri languages and dialects are included in its scope. Balochi and Persian are the three most popular languages in the Aryan Persian group. Also popular in the Indo-Aryan group are Nuristani, Hindi and Dardik language groups. The non-Indo-European language family includes Turkish, Semitic and Seraiki language groups in Afghanistan, the existence of Uyghur, Kyrgyz, Arabic and Zargari languages is currently in question.

I should mention that some of Afghanistan current languages are in danger, or as it should be, they are not well cared for. Therefore, the government needs to take necessary measures to protect its diverse cultural heritage, As long as this right of many nations is protected and strong.

\section{REFERENCES}

Ariana, encyclopedia. (2008). Kabul: academy of sciences of Afghanistan.

Islanov., Mrs. Grasimova. (1963). The national language and literature of Afghanistan.

Serial number of the Pashto community (189) Translated by Motamed shinwari. Kuble: Pashto community.

Rafi, Habibullah. (2017). National line. Kabul: Aman publishing society. 
Shuaa, Basera. (2015). Status of Pashto languages in Aryan languages, Kabul: Afghanistan national Movement.

Shinwari, Dost. (2014). Languages and ethnicities of Afghanistan. Jalalabad: eastern publishing society.

Niazi, Rafiullah. (2014). The status of Pashto language in Indian and Aryan languages (Kabul magazine). Kabul: academy of sciences of Afghanistan.

Yoon, Mohammad Ismail. (2018). History of Pashto literature (ancient period). Kabul: Afghanistan national Movement.

www.toloaFghan.com. 